\title{
Birth Order and Maternal Age for Reported Cases of Severe Prenatal Cortical Hyperostosis (Caffey-Silverman Disease)
}

\author{
Rolf R. Engel, MD ${ }^{1}$ Raul F. Cifuentes, $M D^{1}$ \\ ${ }^{1}$ Departments of Pediatrics, Hennepin County Medical Center and \\ University of Minnesota, Minneapolis, Minnesota \\ Am J Perinatol Rep 2017;7:e174-e180.
}

Address for correspondence Rolf R. Engel, MD, 3265 Snelling Avenue North, Saint Paul, MN 55112 (e-mail: engel014@umn.edu).

\begin{abstract}
The spectrum of prenatal cortical hyperostosis includes a mild phenotype that typically presents after 35 weeks of gestation, and a severe form that presents earlier. The skeletal and systemic manifestations of the severe phenotype remain unexplained. A review of reported cases indicates that older mothers and firstborn infants are

Keywords

- prenatal Caffey disease

- maternal age

- birth order

- difficult intubation overrepresented. This combination suggests decreased fertility. Fourteen years after the birth of the present case, his mother presented with renal failure from multiple myeloma raising the possibility that a maternal antibody may play a role in the etiology of severe prenatal Caffey disease. The present case report is also intended to alert clinicians to potential difficulties with tracheal intubation secondary to micrognathia from mandibular involvement during a critical growth period.
\end{abstract}

The severe form of prenatal Caffey disease is often fatal unless an early delivery interrupts the associated fetal hydrops. A prenatal diagnosis can be made by detecting cortical hyperostosis of the diaphysis of long bones and ribs. Pericardial and abdominal fluid accumulations provide further evidence of fetal compromise. Polyhydramnios is almost always present and placental enlargement has also been reported. Fetal anemia has been attributed to bone marrow encroachment by hyperostosis. The systemic response to inflammation may also contribute to the anemia as leukocytosis, elevated C-reactive protein levels, and an increased erythrocyte sedimentation rate have all been reported for both pre- and postnatal Caffey disease. Once delivered, most of these premature infants require respiratory assistance and hence the advisability of anticipating tracheal intubation in a situation where micrognathia is likely.

\section{Case Report}

The patient was a male infant born at 29 weeks of gestation to a 26-year-old, African American, gravida 6, para 3, aborta 2, mother with blood group AB Rh negative, rubella immunity, and negative results for Rh antibodies, syphylis, gonorrhea, and human immunodeficiency virus. There was no consanguinity and her previous pregnancies were not with this father. The mother's height is $155 \mathrm{~cm}$ and the father's height is normal. Pregnancy was complicated by an upper respiratory infection and anemia with a hemoglobin concentration of $9.0 \mathrm{~g} \%$. From the 4 th month of pregnancy until delivery the mother felt lower abdominal discomfort. She had six prenatal visits. At 7 weeks of gestation, an obstetric ultrasound was normal, but on the day of delivery, it revealed marked polyhydramnios, an enlarged fetal abdominal cavity without evidence of masses or anomalies, and a small pericardial effusion. An amniocentesis done the prior day showed an immature fetal lung profile. The serum $\alpha$-fetoprotein level was normal (41.1). The mother received betamethasone and $\mathrm{MgSO}_{4}$. Due to an abnormal contraction stimulation test and a flat baseline fetal heart rate of $150 / \mathrm{min}$, the infant was delivered by C-section. Apgar scores were 5, 6, and 7 at 1, 5, and 10 minutes, respectively. In the delivery room, there were multiple unsuccessful attempts to intubate him. He was received

July 24, 2017

accepted

July 26, 2017
DOI https://doi.org/

10.1055/s-0037-1606364. ISSN 2157-6998.
Copyright $\odot 2017$ by Thieme Medical Publishers, Inc., 333 Seventh Avenue, New York, NY 10001, USA. Tel: +1(212) 584-4662.
License terms

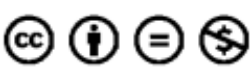


transported to the neonatal intensive care unit while receiving ventilation with a face mask. At 4 hours of age, he was successfully intubated by the ear, nose, and throat staff. Birth weight was $1.33 \mathrm{~kg}$, occipital-frontal circumference (OFC) 26 $\mathrm{cm}$, and length $37.5 \mathrm{~cm}$. His physical examination was remarkable for nonpitting edema of the scalp, chest, and extremities. There was a cobblestone feeling to upper arms, forearms, and shins with limitation in their range of motion. Facial features included a flat face with frontal bossing, proptosis, hypertelorism, marked micrognathia, and glossoptosis. The liver edge was palpated $3.5 \mathrm{~cm}$ below the costal margin, as was the tip of the spleen. He presented with respiratory distress syndrome which responded to positive pressure ventilation and a single dose of lung surfactant. The initial chest X-ray showed cardiomegaly which resolved by the 9th day. An echocardiogram at the age of 12 hours revealed right atrial and right ventricular enlargement and severely diminished right ventricular contractility. Left ventricular size was normal, but contractility was moderately diminished. There was left to right shunting through a patent ductus arteriosus with a peak velocity of $0.6 \mathrm{~m} / \mathrm{s}$.

Transient hypoglycemia on the first day resolved with intravenous glucose infusion. He had anemia with hemoglobin $9.7 \mathrm{~g} / \mathrm{dL}$, hematocrit $30.5 \%$, mean corpuscular volume 124.8 , mean corpuscular hemoglobin 39.8 , mean corpuscular hemoglobin concentration 31.9 , and red blood cell distribution width 20.9. His blood group was B Rh positive with a negative Coombs' test. The leukocyte differential showed 27 neutrophils, 8 bands, 61 lymphocytes, and 8 monocytes, leukocytosis of $44.6 \mathrm{~K} / \mathrm{mm}^{3}$, without left shift that normalized by the 4th day of life and remained normal. The initial platelet count was $149 \mathrm{~K} / \mathrm{mm}^{3}$. Mild thrombocytopenia developed on the 2nd day, decreasing to $86 \mathrm{~K} / \mathrm{mm}^{3}$ and returning to normal in the second week of life. Coagulation studies showed a prothrombin time of $19.3 \mathrm{sec}-$ onds, international normalized ratio 1.7 , activated partial thromboplastin time 48.7 seconds, thrombin time 20.4 seconds, fibrinogen $111 \mathrm{mg} / \mathrm{dL}$, and fibrin degradation products (D-dimer) more than 1,000. The abnormal coagulation values corrected in a few days without specific intervention. C-reactive protein was $14.7 \mathrm{mg} / \mathrm{dL}$ on admission and normalized 6 days later, remained within normal limits throughout his hospitalization, except for a rise during a septic episode. Indirect hyperbilirubinemia up to $10.8 \mathrm{mg} / \mathrm{dL}$ developed on his 3rd day and was treated with a 5-day course of phototherapy. Direct hyperbilirubinemia was noted on the 3rd day, reaching $5.9 \mathrm{mg} / \mathrm{dL}$ on the 4 th day, and was still present by the 36 th day with a level of $1.4 \mathrm{mg} / \mathrm{dL}$. Liver enzymes on the 2 nd day were alkaline phosphatase $266 \mathrm{IU} / \mathrm{L}$, alanine transaminase (ALT) 76 IU/L, and aspartate transaminase (AST) 277 IU/L. Five days later, both ALT and AST were normal. The 5' nucleotidase was $45 \mathrm{U} / \mathrm{L}$, the plasma total protein concentration was $5.4 \mathrm{~g} / \mathrm{dL}$ with an albumin level of $2.8 \mathrm{~g} / \mathrm{dL}$. Plasma magnesium was $4.0 \mathrm{mg} / \mathrm{dL}$ and calcium was $8.9 \mathrm{mg} / \mathrm{dL}$ with transient hypocalcemia of $6.4 \mathrm{mg} / \mathrm{dL}$ occurring on the 3rd day. All these tests became normal in the following days. Ammonia was $55 \mu \mathrm{Mol} / \mathrm{L}$ on the 4th day. Cephalic ultrasound was normal on the 2 nd and 15 th days. Transient seizure-like activity was noted on the 3rd day and was treated with phenobarbital for the remaining hospitalization, although an electroencephalogram was normal. Ophthalmologic examination revealed mild clouding of the corneas, a hazy vitreous in the right eye, and immature retinas. A renal ultrasound was normal. The newborn metabolic screen was normal with no evidence of a hemoglobinopathy.

A 30-cell metaphase G-banding disclosed a normal 46XY karyotype without cytogenetic abnormalities. The most striking finding on admission was the radiological appearance of the long bones. Thick, periosteal new bone formation was seen in the mandible, ribs, arms, tibias, and fibulas (-Figs. 1 and 2). The clavicles appeared normal.

He was treated with ampicillin and gentamicin for the first 7 days; however, blood cultures were negative. Tube feedings were started on day 10 and gradually advanced as he intermittently had abdominal distention, requiring periods of no gastric feedings. He received central intravenous nutrition until 2 days before his death. On the 13th day, the initial $2.5 \mathrm{~mm}$ endotracheal tube was replaced with a $3.0-\mathrm{mm}$ tube in the operating room. After this, he remained ventilator dependent with moderately low settings and $\mathrm{FiO}_{2}$

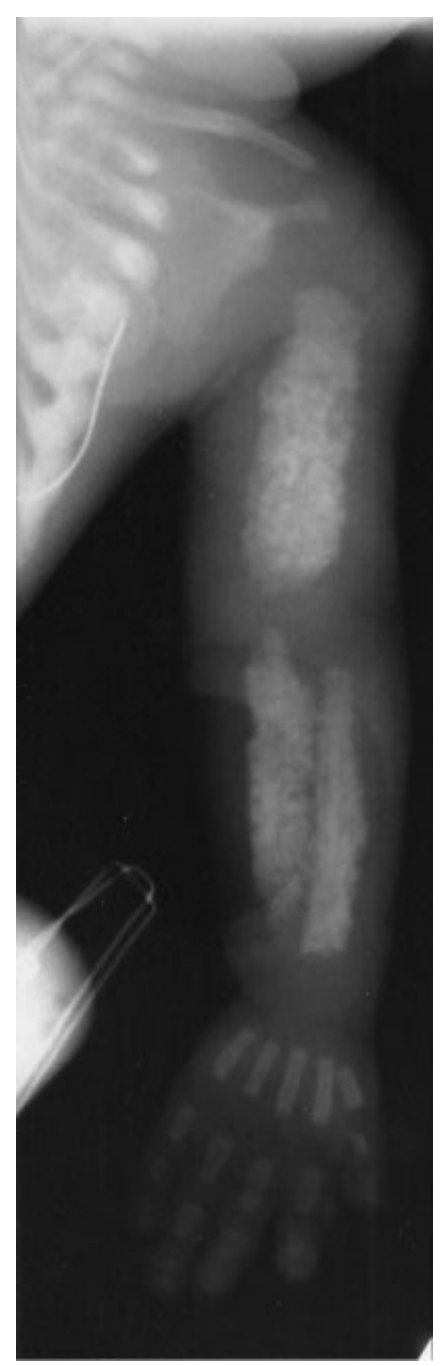

Fig. 1 Striking hyperostosis of humerus, radius, ulna, and ribs on the day of his birth. Clavicle, scapula and hand bones are unaffected. 


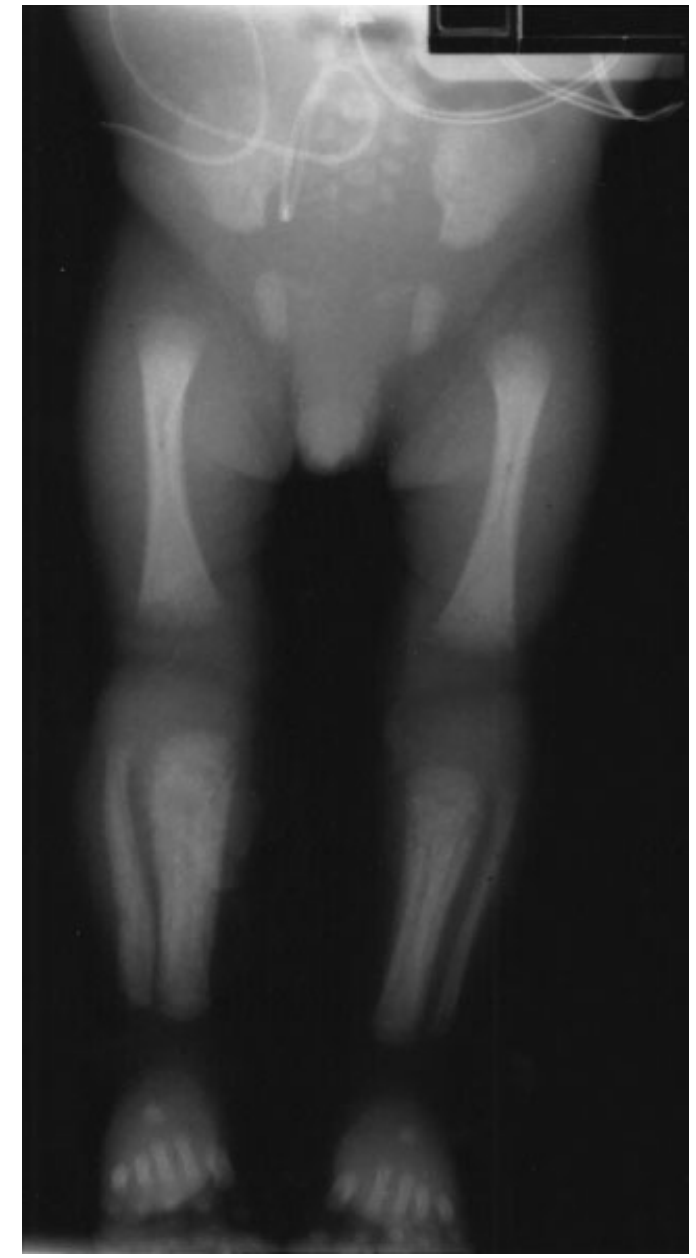

Fig. 2 Bilateral hyperostosis of tibias and fibulae on his first day of life. The left tibia and both fibulae have thick periosteal new bone formation. There is soft tissue swelling.

below 0.3 . On the 18th day, he was started on a 7-day course of vancomycin for a blood culture that was positive for coagulase-negative Staphylococcus. The ductus arteriosus was surgically ligated on the 26th day, after three unsuccessful attempts to close it with indomethacin. He received seven packed red cell transfusions during his hospitalization. Prednisolone at $1.5 \mathrm{mg} / \mathrm{kg} / \mathrm{d}$ was started on the 9th day and slowly weaned to $0.2 \mathrm{mg} \mathrm{mg} / \mathrm{kg} / \mathrm{d}$ orally at 33 days. Later, he was started on oral ibuprofen. Because of blood in the stools, ibuprofen was discontinued after 3 days of therapy. The physical exam, laboratory tests, and abdominal flat plate were all unremarkable.

On the 38th day, he again developed feeding intolerance, followed by stools with streaks of blood, abdominal distention, pneumatosis intestinalis, metabolic acidosis, thrombocytopenia, shock, and hyperkalemia. He succumbed to necrotizing enterocolitis the same day. His weight was $1.895 \mathrm{~kg}, \mathrm{OFC} 30 \mathrm{~cm}$, and length $43 \mathrm{~cm}$.

The autopsy revealed a 140-g enlarged liver with foci of erythropoiesis, and a 9-cm necrotic small intestinal loop proximal to the terminal ileum with ulcerations of the mucosa. There were fibroproliferative changes in the lungs, consistent with bronchopulmonary dysplasia.
The placenta dimensions were weight $766 \mathrm{~g}$ with a triangular shape measuring $37 \times 38 \mathrm{~cm}$ and thickness $3 \mathrm{~cm}$. This is larger than the reported ${ }^{1}$ mean for 29 weeks of gestation: weight of $306 \mathrm{~g}$, diameter $16 \mathrm{~cm}$, and thickness $2.1 \mathrm{~cm}$. The cytological morphology was mature with some scattered edematous villi. The number of nucleated erythrocytes was increased in the fetal vessels.

Twenty years later, a paraffin block sample of his liver was tested for a mutation in COL 1A1 at the Collagen Diagnostic Laboratory, University of Washington, Seattle, WA. Neither the common pathogenic variant (COL $1 \mathrm{~A} 1 \mathrm{c.3040C}>\mathrm{T}$, p. Arg1014Cys, Arg836Cys in the triple helix) nor the rare variant (COL 1A1:c.2752 > T,p.Arg918Cys, Arg740Cys in the triple helix) for Caffey disease were identified.

The mother has had no further pregnancies. Her previous three children are all healthy. At the age of 40 years, she was diagnosed to have multiple myeloma with immunoglobulin $\mathrm{G}$ kappa light chain monoclonal gammopathy. This has resulted in multiple skeletal lesions and renal failure requiring dialysis. Her only sister has HLA-B27 positive ankylosing spondylitis and her only brother has HLA-B27 positive rheumatoid arthritis.

\section{Maternal Age and Birth Order}

We found 29 published case reports (including the above) of congenital cortical hyperostosis, delivered before 35 weeks of gestation, that included the mother's age at delivery and the birth order. Reports that lacked either the maternal age or parity were excluded. Although each of these cases presented before 35 weeks of gestation, there is heterogeneity in their outcome, ranging from abortion ${ }^{2,3}$ to stillbirth ${ }^{4-11}$ to postnatal death on the first day ${ }^{5,12-17}$ to death from 10 to 38 days $^{3,18}$ (present case) to discharge from the hospital with ${ }^{19-24}$ and even without ${ }^{25}$ initial respiratory impairment.

These case reports represent a diversity of cultures over 73 years, a time span over which many groups have had an upward shift in the average maternal age at delivery. The median, mean, and mode for the year of birth were all within 1 year of 1995. Therefore, our choice of using the U.S. population from 2015 as a control group is biased against the hypothesis that this cohort of affected infants has older mothers than the general population. Despite this limitation, the distribution of maternal ages at delivery was shifted upward for the 29 cases as compared with the general population of U.S. mothers (- Fig. 3). In comparison to all mothers in the United States between 1980 and 2015, the fraction of mothers who were 35 years or older at the time of delivery was greater for the affected births (28\%) (-Fig. 4).

Although older mothers can be expected to deliver fewer firstborn infants than a random sample of mothers, the above cohort of births had a greater percentage of firstborn infants (58.6\%) than the control group (-Fig. 4). This result could indicate that on average the parents of these infants had reduced fertility. It is not clear whether such a decrease in fertility tracks with the mother, father, or the combination. One mother ${ }^{10}$ had in vitro fertilization after 6 years of infertility. Both mothers who had two affected infants did so with no change in paternity. ${ }^{3,5}$ Among the other 10 mothers who had 


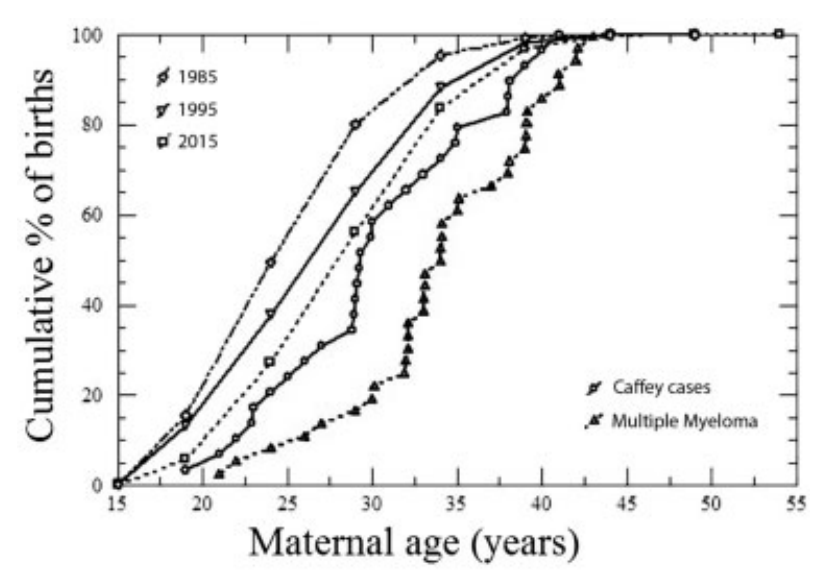

Fig. 3 Maternal age and cumulative percentage of births with infantile cortical hyperostosis before 35 weeks of gestation (line with circles) and for births in the United States from the general population in 1980 (line with diamonds), 1995 (line with inverted triangles), and 2015 (line with squares). The distribution is right shifted for infants with Caffey disease $(n=29)$. There is a further right shift for infants with maternal multiple myeloma ( $n=36$ ) (line with triangles).

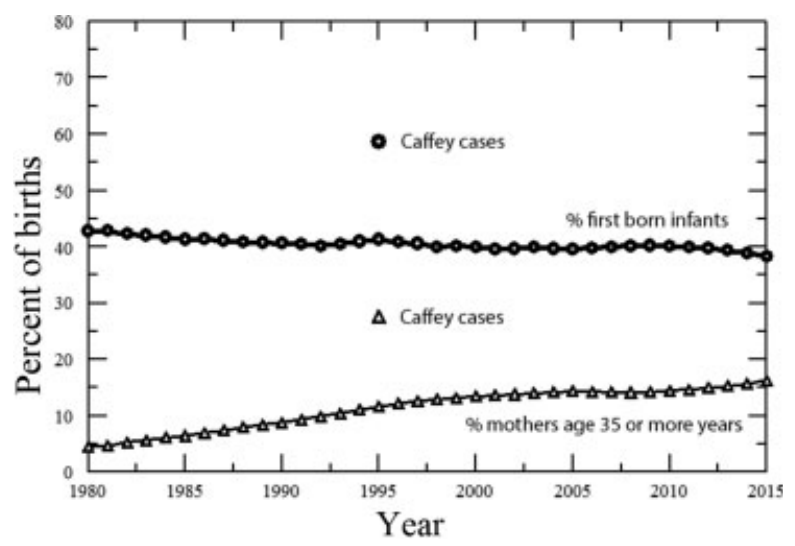

Fig. 4 Percentage of firstborn births (circles) and percentage of births delivered by mothers aged 35 or more years (triangles) for the general population (lines) and for cases of infantile cortical hyperostosis (Caffey disease) presenting before 35 weeks of gestation (single triangle and circle). The control data from 1980 to 2015 is from the Communicable Disease Center. The Caffey cases have been arbitrarily plotted above 1995 because that was the mode year for this group.

an affected infant after one or more normal infants, there were three examples where the paternity changed for the affected infant $^{4,16}$ (present case). Parental consanguinity was reported for 1 of the 27 mothers. ${ }^{25}$ Five of the 27 mothers $3,14,17,23$ (present case) had a combined total of 10 pregnancies that ended in abortions where no diagnosis of Caffey disease was made. These pregnancies have been excluded when determining the birth order since the same was done with the definition of birth order for the control group.

\section{Sources and Statistical Analysis}

To determine whether the group of 29 infants with prenatal Caffey disease is representative of the general population regarding maternal age and birth order, comparisons were made with U.S. data for 2015 from the Communicable Disease
Center. The presumption was that if the affected infants had a significantly higher maternal age than the control group in 2015, then this should also apply for prior years since the average maternal age has been trending upward. The same argument does not apply to birth order. However, this variable has remained more stable as compared with the upward drift in maternal age over time (-Figs. 3 and 4 ). The fact that only 7 of the 29 infants were born in the United States and the remaining 22 infants were born in 12 other countries is a limitation of this analysis that was not addressed. Maternal age and parity were reported for 29 affected infants including the present report. ${ }^{2-25}$ The references for 36 infants born to mothers with multiple myeloma (plotted in - Fig. 3) appear in two review articles. ${ }^{26,27}$

The chi-square analysis was significant at $p<0.03$ for the probability that the group of 29 cases of Caffey disease was a random sample from the larger control group (of U.S. infants in 2015) when matched for the proportion of infants with maternal age 35 or older years (8/29) and the proportion of firstborns (17/29).

To erase any doubt about the validity of the chi-square result due to the small sample size, an exact calculation based on the underlying multinomial distribution was performed using Mathematica and was significant at $p<0.02$.

\section{Discussion}

In 1957, Caffey wrote "It is my belief that study of the mother will finally unravel the cause and pathogenesis of this disease in the infant." ${ }^{28}$ Caffey observed that infants with this disease are frequently born to mothers who are 30 years of age or older. $^{29}$ The present report supports this observation for infants who present before 35 weeks of gestation. We have not reviewed the maternal age distribution for cases born after this stage of development. Because these mothers as a group also had fewer prior children, it is possible that the same process that produced prenatal cortical hyperostosis in their affected child could have also reduced their prior fertility. Such a sequence may favor a genetic etiology but it does not preclude alternative explanations such as an infectious, immunologic, or inflammatory process. With a better understanding of the pathogenesis, it may become apparent whether more than one diagnosis is represented by this group of 29 cases.

The earlier the onset of prenatal Caffey disease, the greater the interference with bone growth. This relationship is demonstrated by decreased rib growth with smaller thoracic cavity and more pulmonary hypoplasia in the most immature cases. This group also has the shortest limbs and the most marked micrognathia. Two case reports of dysplastic cortical hyperostosis (Kozlowski-Tsuruta syndrome $)^{30,31}$ were excluded because the authors concluded that they represent a form of dwarfism.

The present case, from 1995, demonstrates that it is possible to use paraffin block samples of liver to retrospectively test for mutations in a gene for collagen synthesis that was first reported by Gensure et al in 2005 for the less severe form of prenatal Caffey disease. ${ }^{32}$ The absence of this mutation is typical for the severe, prenatal form of Caffey 


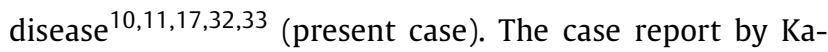
moun-Goldrat et $\mathrm{al}^{2}$ is an exception.

The milder form of prenatal cortical hyperostosis has been reported in a female rhesus monkey and one of her male offspring. ${ }^{34}$ There is also a report of congenital cortical hyperostosis in pigs. ${ }^{35}$ In the case of a canine model of postnatal Caffey disease, Hytönen et al have recently reported a mutation in a gene (SLC37A2) that codes for a glucose-phosphate transporter. $^{36}$

The present case had signs of inflammation at the time of birth, as has previously been reported for other cases. These included elevated C-reactive protein levels, leukocytosis, and possibly the direct hyperbilirubinemia. The first case of Al-Tawil et $\mathrm{al}^{22}$ also had elevated immunoglobulin $\mathrm{M}$ as did the case of Lécolier et al $(12.4 \mathrm{mg} / \mathrm{L}) .{ }^{37}$ To reconcile this with the failed attempts to detect an associated pathogen, Nistala et $\mathrm{al}^{38}$ have proposed a sequence, involving cytokines, whereby an inappropriate immune or inflammatory response could be triggered by either a new mutation or the one reported by Gensure et al. ${ }^{32}$

We hesitate to dismiss maternal multiple myeloma in the present case as a coincidence because this plasma cell tumor is uniformly preceded by a prodromal period during which there is a monoclonal gammopathy of undetermined significance (MGUS). ${ }^{39,40}$ MGUS has been detected at least 20 years before the diagnosis of multiple myeloma. ${ }^{41}$ The mother of the present case presented with edema from renal failure at the age of 40 years which was 14 years after the birth of her affected son. There is a precedent for longer latencies between the transplacental transmission of maternal antibodies and the first manifestation of maternal disease. Kasinath and Katz reported a mother who gave birth to three sons with congenital heart block, but she did not have evidence of lupus until 16 years after the birth of the first boy. ${ }^{42}$ We could not find a report where maternal monoclonal gammopathy or multiple myeloma resulted in an infant with Caffey disease. However, transient neonatal renal failure, ${ }^{43}$ von Willebrand syndrome, ${ }^{44}$ and cryoglobulinemia ${ }^{45,46}$ have been linked to maternal monoclonal antibodies traversing the placenta.

There are reports of infertility in mothers with MGUS. 47,48 Lee et $\mathrm{al}^{49}$ reported a 32-year-old mother with MGUS for 7 years before a successful pregnancy after several years of infertility and a failed attempt at in vitro fertilization. Since multiple myeloma is rare before the age of 40 years ( $<3 \%$ of cases), it is unusual to encounter this malignancy in pregnancy. In reviewing 36 reports of multiple myeloma and pregnancy, we found two instances where mothers had in vitro fertilization ${ }^{50}$ and two reports of pharmacologically induced ovulation. ${ }^{48,51} \mathrm{~A}$ plot of maternal age versus the cumulative percentage of births shows a right shift toward older ages for mothers with multiple myeloma (-Fig. 3). Whether this is entirely consequent to the higher incidence of plasma cell disorders with increasing age or whether reduced fertility is also a factor is not clear from these data. Based on observations on monkeys, Chryssikopoulos et al have proposed that failure to achieve a normal drop in the immunoglobulin level in the fallopian tube fluid at the time of ovulation could explain reduced fertility in women with hypergammaglobulinemia. ${ }^{47}$
If a maternal antibody is involved in the genesis of prenatal Caffey disease, then the fetal antigen remains to be identified. In the case where a normal child is born subsequent to an affected infant, ${ }^{5}$ the father may be heterozygous for that hypothetical fetal antigen.

The present case is typical of the severe prenatal form for both the skeletal and the systemic manifestations. However, the placental enlargement (766 g) exceeded previous reports by Kamoun-Goldrat et $\mathrm{al}^{2} 577 \mathrm{~g}$, de Jong and Muller ${ }^{5} 620 \mathrm{~g}$, and Bercau et $\mathrm{al}^{9} 240 \mathrm{~g}$. Microscopically, edema of scattered villi has been observed by de Jong et al, ${ }^{5}$ Wright et al, ${ }^{16}$ and in the present case. Compared with erythroblastosis, the placental enlargement and fetal hydrops are greater than expected for a hemoglobin of $9.7 \mathrm{~g} \%$ in the present case and $11.9 \mathrm{~g} \%$ for the fetal demise reported by Lécolier et al. ${ }^{37}$ Maternal anemia, systemic inflammation in the fetus, and possibly in utero fever could exaggerate the effect of fetal anemia. The fixed fetal heart rate of 150 in the present case was attributed to fetal hypoxia.

Despite unsolved mysteries relating to the etiology of preterm Caffey disease, the prognosis is favorable for those who survive the perinatal period. ${ }^{17,19}$ As illustrated by the present case and other reports, ${ }^{13,14}$ tracheal intubation can present a challenge because of micrognathia, $5,11,16,18,22$ retrognathia, ${ }^{2,5,7,10,19}$ microstomia, ${ }^{10}$ underdeveloped mandible, ${ }^{17}$ and glossoptosis. Periosteal edema, over the affected mandible, may further complicate efforts to intubate these premature infants.

Since Roske reported ${ }^{51}$ the first postnatal case of infantile cortical hyperostosis in 1930, a descendant of that case has been found to have the same disease. ${ }^{52,53}$ The genetic etiology is also confirmed by other families where either parent and an affected child carry the same mutation in collagen synthesis. However, this mutation is not found in most cases presenting before 35 weeks of gestation. Also, a mutation alone does not explain the higher incidence of sporatic postnatal infantile cortical hyperostosis that occurred in North America between 1945 and 1965 but not since that era and not in other continents. ${ }^{24,54}$ An infectious agent that elicits a cross-reacting immune response to an antigen on growing bone in some infants could explain the outbreak of cases observed by Caffey and Silverman. Alternatively, reports of prostaglandin-induced cortical hyperostosis $^{55}$ invite speculation that exogenous agents might also have this effect. Extending the present study of maternal age and parity to a larger group of preterm cases and to a group of postnatal cases may further delineate these two phenotypes of Caffey disease.

\section{Conclusion}

We can reject the null hypothesis that this sample reflects typical proportions of firstborns and older mothers at the $2 \%$ significance level.

Note

This study was approved by the Human Subjects Research Committee at Hennepin County Medical Center. Neither author has a competing financial interest to declare. 


\section{Acknowledgments}

The authors thank Peter DeLong for the statistical analysis; Peter Byers, MD, for the genetic analysis; Lisa Berg for assisting in reference searches; Bradley Linzie, MD, for reviewing the histology; Uta Francke, MD, for guidance; and Richard Lussky, MD, for clinical care.

\section{References}

1 Benirschke K, Burton G, Baergen R. Pathology of the Human Placenta. 6th ed. Berlin: Springer Verlag; 2012

2 Kamoun-Goldrat A, Martinovic J, Saada J, et al. Prenatal cortical hyperostosis with COL1A1 gene mutation. Am J Med Genet A 2008;146A(14):1820-1824

3 Drinkwater BM, Crino JP, Garcia J, Ogburn J, Hecht JT. Recurrent severe infantile cortical hyperostosis (Caffey disease) in siblings. Prenat Diagn 1997;17(08):773-776

4 Jenkinson E, Pfisterer WH, Latteier KK, Martin M. A prenatal diagnosis of osteopetrosis. Am J Roentgen 1943;49(04):455-462

5 de Jong G, Muller LM. Perinatal death in two sibs with infantile cortical hyperostosis (Caffey disease). Am J Med Genet 1995;59 (02):134-138

6 Labrune M, Guedj G, Vial M, Bessis R, Roset M, Kerbrat V. Maladie de Caffey à début anténatal. Arch Pediatr (Barc) 1983;40:39-43

7 Burton KR, Glanc P. Prenatal presentation of lethal variant infantile cortical hyperostosis (Caffey disease). Ultrasound Q 2016; 32(04):338-341

8 Bennett HS, Nelson TR. Prenatal cortical hyperostosis. Br J Radiol 1953;26(301):47-49

9 Bercau G, Gonzalez M, Afriat R, Lecolier B, de Kermadec S. La difficulté du diagnostic de la maladie de Caffey in utero. A propos d'un cas simulant l'ostéogenèse imparfaite létale. Ann Pediatr (Paris) 1991;38(01):15-18

10 Tülek F, Kahraman A, Keskin M, Kan Ö. Antenatal diagnosis of prenatal cortical hyperostosis: case report. Turkiye Klinkler J Gynecol Obs 2014;24(04):253-256

11 Darmency V, Thauvin-Robinet C, Rousseau T, et al. Contribution of three-dimensional computed tomography in prenatal diagnosis of lethal infantile cortical hyperostosis (Caffey disease). Prenat Diagn 2009;29(09):892-894

12 Srisantiroj N, Padungkiatwattana P, Sirijareonthai S, et al. Prenatal cortical hyperosthosis: Caffey disease. 2010. Available at: sonoworld.com/thefetus/page.aspx?id=2777. Accessed March 21, 2017

13 Pomerance HH, Wallis-Crespo C, Barness EG. Lethal infantile cortical hyperostosis. Fetal Pediatr Pathol 2005;24(02):89-94

14 Langer R, Kaufmann HJ. Pränatale Diagnosestellung bei Caffey'scher Erkrankung (infantile kortikale Hyperostose). Klin Padiatr 1985; 197(06):473-476

15 Faul R. [Familial appearance of infantile cortical hyperostosis (CaffeySilverman syndrome)]. Arch Kinderheilkd 1961;164:271-276

16 Wright JR Jr, Van den Hof MC, Macken MB. Prenatal infantile cortical hyperostosis (Caffey's disease): a 'hepatic myeloid hyperplasia-pulmonary hypoplasia sequence' can explain the lethality of early onset cases. Prenat Diagn 2005;25(10):939-944

17 Dahlstrom JE, Arbuckle SM, Kozlowski K, et al. Lethal prenatal onset infantile cortical hyperostosis (Caffey disease). Pathology 2001;33(04):521-525

18 Al-Harbi M, Barakat N, Shabaan W, Yousef H. Prenatal Caffey disease case report and review of the literature. Med J Cairo Univ 2014;82(01):625-628

19 Hoen N, Cagneaux M, Combourieu D, et al. Prenatal Caffey disease (prenatal cortical hyperostosis): severe forms with favorable outcome. Prenat Diagn 2015;35(04):409-411

20 Schärer K, Szabo J. Familiäre infantile corticale hyperostose mit pränatalem Beginn. Roentgenfortschritte 1966;106(02):154-163

21 Herman TE. Antenatal-onset infantile cortical hyperostosis and nonimmune hydrops. J Perinatol 1996;16(2 Pt 1):137-139
22 Al-Tawil KI, Ahmed GS, Al-Hathal MM, Al-Zuwayed MA. Sporadic congenital infantile cortical hyperostosis (Caffey's disease). Am J Perinatol 1998;15(11):629-633

23 Hochwald O, Osiovich H. Prenatal Caffey disease. Isr Med Assoc J 2011;13(02):113-114

24 Marshall GS, Edwards KM, Wadlington WB. Sporadic congenital Caffey's disease. Clin Pediatr (Phila) 1987;26(04):177-180

25 Kroon ND, Smith F, Sanghavi R, Sarkar P. Prenatal cortical hyperostosis (Caffey disease) with Down syndrome. J Obstet Gynaecol 2009;29(01):57-58

26 Cabañas-Perianes V, Macizo M, Salido E, et al. 'Management multiple myeloma during pregnancy: a case report and review'. Hematol Oncol 2016;34(02):108-114

27 Jurczyszyn A, Olszewska-Szopa M, Vesole AS, et al. Multiple myeloma in pregnancy-A review of the literature and a case series. Clin Lymphoma Myeloma Leuk 2016;16(03):e39-e45

28 Caffey J. Infantile cortical hyperostosis; a review of the clinical and radiographic features. Proc R Soc Med 1957;50(05):347-354

29 Sidbury JB Jr, Sidbury JB. Infantile cortical hyperostosis; an inquiry into the etiology and pathogenesis. N Engl J Med 1954; 250(08):309-314

30 Kozlowski K, Tsuruta T. Dysplastic cortical hyperostosis: a new form of lethal neonatal dwarfism. Br J Radiol 1989;62(736):376-378

31 Suri M, Garrett C, Winter RM, Hall CM, Griffiths M. Dysplastic cortical hyperostosis (Kozlowski-Tsuruta syndrome): report of a second case. Clin Dysmorphol 2002;11(04):267-270

32 Gensure RC, Mäkitie O, Barclay C, et al. A novel COL1A1 mutation in infantile cortical hyperostosis (Caffey disease) expands the spectrum of collagen-related disorders. J Clin Invest 2005;115(05):1250-1257

33 Schweiger S, Chaoui R, Tennstedt C, Lehmann K, Mundlos S, Tinschert S. Antenatal onset of cortical hyperostosis (Caffey disease): case report and review. Am J Med Genet A 2003;120A (04):547-552

34 Snook SS, King NW Jr. Familial infantile cortical hyperostosis (Caffey's disease) in rhesus monkeys (Macaca mulatta). Vet Pathol 1989;26(03):274-277

35 Uetsuka K, Suzuki T, Ogawa H, Sato H, Doi K, Nunoya T. A case of congenital hyperostosis in a newborn piglet. J Vet Med Sci 2012; 74(02):259-262

36 Hytönen MK, Arumilli M, Lappalainen AK, et al. Molecular characterization of three canine models of human rare bone diseases: Caffey, van den Ende-Gupta, and Raine syndromes. PLoS Genet 2016;12(05):e1006037

37 Lécolier B, Bercau G, Gonzalès M, et al. Radiographic, haematological, and biochemical findings in a fetus with Caffey disease. Prenat Diagn 1992;12(08):637-641

38 Nistala H, Mäkitie O, Jüppner H. Caffey disease: new perspectives on old questions. Bone 2014;60:246-251

39 Weiss BM, Abadie J, Verma P, Howard RS, Kuehl WM. A monoclonal gammopathy precedes multiple myeloma in most patients. Blood 2009;113(22):5418-5422

40 Landgren O, Kyle RA, Pfeiffer RM, et al. Monoclonal gammopathy of undetermined significance (MGUS) consistently precedes multiple myeloma: a prospective study. Blood 2009;113(22):5412-5417

41 Kyle RA, Therneau TM, Rajkumar SV, et al. A long-term study of prognosis in monoclonal gammopathy of undetermined significance. N Engl J Med 2002;346(08):564-569

42 Kasinath BS, Katz AI. Delayed maternal lupus after delivery of offspring with congenital heart block. Arch Intern Med 1982;142 (13):2317

43 Dolfin T, Pomeranz A, Korzets Z, et al. Acute renal failure in a neonate caused by the transplacental transfer of a nephrotoxic paraprotein: successful resolution by exchange transfusion. Am J Kidney Dis 1999;34(06):1129-1131

44 Nageswara Rao AA, Rodriguez V, Long ME, Winters JL, Nichols WL, Pruthi RK. Transient neonatal acquired von Willebrand syndrome due to transplacental transfer of maternal monoclonal antibodies. Pediatr Blood Cancer 2009;53(04):655-657 
45 Laugel V, Goetz J, Wolff S, Beladdale J, Sibilia J, Messer J. Neonatal management of symptomatic transplacental cryoglobulinaemia. Acta Paediatr 2004;93(04):556-558

46 Sibilia J, Feugeas O, Laugel V, Dreval A, Messer J, Goetz J. Successful management of neonatal cryoglobulinaemia after a gemellar pregnancy in a woman with symptomatic type I cryoglobulinaemia. Ann Rheum Dis 2004;63(02):217-218

47 Chryssikopoulos A, Dalamaga AL, Hassiakos D. Monoclonal gammopathy of unknown significance in pregnancy. Clin Exp Obstet Gynecol 1997;24(01):31-32

48 Willmott F, Agarwal N, Heath M, Stevens J, Chakravarti S. Plasma cell myeloma diagnosed in pregnancy. BMJ Case Rep 2010;2010: bcr0420102901

49 Lee JC, Francis RS, Smith S, Lee R, Bingham C. Renal failure complicating myeloma in pregnancy. Nephrol Dial Transplant 2007;22(12):3652-3655
50 Khot AS, Prince HM, Harrison SJ, Seymour JF. Myeloma and pregnancy: strange bedfellows? Leuk Lymphoma 2014;55(04):966-968

51 Roske G. Eine eigenartige Knochenerkrankung im Säuglingsalter. Monatschrift fur Kinderheilkd 1930;47:385-400

52 Veller K, Laur A. Zur Ätiologie der infantilen kortikalen Hyperostose (Caffey-Syndrom). Fortschr Geb Rontgenstr Ver Rontgenprax 1953;79(10):446-452

53 Maclachlan AK, Gerrard JW, Houston CS, Ives EJ. Familial infantile cortical hyperostosis in a large Canadian family. Can Med Assoc J 1984;130(09):1172-1174

54 Harris VJ, Ramilo J. Caffey's disease: a case originating in the first metatarsal and review of a 12 year experience. AJR Am J Roentgenol 1978;130(02):335-337

55 Woo K, Emery J, Peabody J. Cortical hyperostosis: a complication of prolonged prostaglandin infusion in infants awaiting cardiac transplantation. Pediatrics 1994;93(03):417-420 